I wonder whether I was alone in having such an experience but suspect not and would be grateful to hear of others' experiences and any successful strategies that may be enacted.

N. S. BRown, Solihull Healthcare NHS Trust, Lyndon Resource Centre, Hobs Meadow, Solihull, West Midlands B92 8PW

\section{Trainees' understanding of services}

Sir: It is encouraging to learn of trainees' interest in learning about the past and future pressures that shape our service (Gaughran \& Davies, Psychriatric Bulletin. February 1995. 19, 121-122).

Sub-specialisation has occurred extensively in many medical specialities, and concern about the inadequate support of general services has been voiced often. It is essential that the right balance is struck between subspecialisation and the general service provision, and the driving principle based on outcomes rather than rhetoric; for example, following guidance on the differing morbidity and mortality rates for vascular surgery. Resources should follow outcomes but there are many examples in psychiatry where there is pitiably poor support for a locality's service provision.

Like old age psychiatry, adolescent psychiatry developed as a body of knowledge and practice in response to poorly met needs. It might be broadly defined as the general psychiatry of adolescence', and, where inpatient provision exists, the assessment and treatment of psychotic illness of adolescentonset should be a primary task. The contemporary literature clearly supports that stance and, instead of internecine quarrelling in the profession, hard decisions on resource allocation made on the basis of what can be afforded and where the best outcomes can be ensured, so that the needs of patients and their clinical services are supported to the maximum that NHS funding permits.

R. M. WRATE, Edinburgh Healthcare NHS Trust, Royal Edinburgh Hospital, Edinburgh EH1O $5 H F$

\section{Out of Darkness video}

Sir: Jacqueline Atkinson writes (Psychiatric Bulletin, January 1995, 19, 43) about the video Out of Darkness starring Diana Ross which describes the recovery of a schizophrenic patient on clozapine. The criticisms which she levels "stress mentioned only in passing" and the presence of stereotypes and the fact that "we learn little of the chronic negative symptoms" and many similar remarks sound like she is refereeing an academic paper.

This is a simple video made for the viewing lay public with accurate technical input from one of the world's major experts on schizophrenia in general and clozapine in particular. Of course the film offers hope, and as a clinician with nearly 25 years of experience I welcome anything that offers hope in contrast with the dreadful legacy that schizophrenic patients and their families have endured in so-called civilised countries this century.

I have shown the video to many of the families of my clozapine patients and they love it. The best of luck to them, God knows they deserve it and let us not try to denigrate simple entertainment using pseudo-academia.

Michael Launer, Burnley Health Care NHS Trust, Burnley General Hospital, Burnley $B B 102 P Q$

Sir: Out of Darkness (certificate 15), whatever else it does, promotes clozapine. That it also entertains means that it reaches a wider public than would a television documentary. In the month of its release (August 1994) my local video shop's two copies were borrowed 26 times (2-day hire), showing its popularity.

People are susceptible to messages about mental illness portrayed in the media (e.g. Brookside, Eastenders) (University of Glasgow Media Group 1993a, b). There is also a suggestion that, in this area, media messages may outweigh personal experience for some people. To pretend that films such as Out of Darkness elicit no response other than 'entertainment' is naive. It might be unrealistic to expect any media message/ entertainment to be unbiased but to point out bias can be merely to refer to ones' own experience and reality, not 'pseudo-academia'. Surely by showing the film to patients' families Dr Launer is treating it as something other than 'simple entertainment' (education?, to promote discussion? to confirm the use of 